\title{
Falsified Medicines in the European Union and North America: What are we doing to Protect Public Health?
}

Julia Laín Abril ${ }^{1 *}$, David W Holt ${ }^{2}$ and Richard R Wilson ${ }^{3}$

1153 Cromwell Road, SW50TQ London, UK

${ }^{2}$ Emeritus Professor of Bioanalytics, Analytical Services International, St George's - University of London, SW17 ORE, London, UK

${ }^{3}$ Graham School, University of Chicago, Chicago, USA

*Corresponding author: Julia Laín Abril, 153 Cromwell Road, SW50TQ London, UK, Tel: 447415717740; E-mail: Julia.abril.14@ucl.ac.uk

Received date: May 30, 2016; Accepted date: June 16, 2016; Published date: June 21, 2016

Copyright: @ 2016 Abril JL, et al. This is an open-access article distributed under the terms of the Creative Commons Attribution License, which permits unrestricted use, distribution, and reproduction in any medium, provided the original author and source are credited.

\begin{abstract}
Falsified medicines are a global healthcare problem of pandemic dimensions. The consequences are not limited to the less regulated countries; they also impact on the more highly regulated ones. Being aware of this global public health crisis, government authorities are developing more stringent environments to impede the breach of the legitimate supply chain. However, to protect public health and raise awareness, cooperation on the part of all legitimate stakeholders and collaboration of not-for-profit organisations are crucial. The healthcare professional, as last link of the supply-and-distribution chain, is responsible for the medicines provided and needs to be able to guarantee the quality and safety to ensure the wellbeing of patients. Protecting the health of the patient and ensuring high quality, safe and effective medicines must be the highest priority of healthcare providers and the pharmaceutical industry. This short review analyses the efforts and approaches by different governments in the European Union and North America to abolish the presence of falsified medicines in the market and poses important questions to improve the role of healthcare professionals in this important global health matter.
\end{abstract}

Keywords: Falsified medicines; European Union; North America; Regulations; Public health

\section{Introduction}

Falsified medicines are a global healthcare problem of pandemic dimensions. In September 2015 Interpol seized two tons of falsified medicines in 13 Asian countries, including China and India, and more than 150 tones in seven African countries in August 2015. More astonishing was the seizure of 20.7 million falsified and illicit medicines worth USD81 million through an international operation in June 2015 targeting online medicines. Such medicines can be introduced into the legitimate supply chain, reaching patients throughout the world and putting their lives at unnecessary risk.

The consequences are not limited to the less regulated countries; they also impact on the more highly regulated countries. An increase in mortality and morbidity is thought to be a significant consequence of falsified medicines, e.g., counterfeiting HIV antiretrovirals in Thailand may have an immense impact on public health in the developed world by creating mutated strains that may turn effective treatments into dangerous non-efficacious therapies. Falsified medicines are not acceptable because, in addition to putting patients at risk and undermining the public confidence in medicines, it also exposes the vulnerability of the pharmaceutical supply system and jeopardises the credibility of national authorities.

We are aware of this global healthcare problem, we know it is a big problem - but how big is it and what are we doing to tackle it?

Currently there are no regulatory requirements for reporting the detection of falsified medicines, and there are no centralized multinational systems for registering these occurrences and their impact on public health. Official communications from regulatory bodies informing healthcare providers of falsified and unauthorized medicines happen regularly in the European Union (EU) and North America (NA) pharmaceutical markets:

- In April 2015, the United States Food and Drug Administration (FDA) published an alert on a falsified version of botulinum toxinA (Botox ${ }^{\oplus}$, Allergan Plc.). This falsified medicine contained not only the approved botulinum toxin-A but also other forms of botulinum toxin not approved or included in the botulinum toxinA pharmaceutical.

- In April 2014, the European Medicines Agency (EMA) published a warning for nine batches of trastuzumab(Herceptin, Roche Holding Ag) vials stolen from Italian hospitals that later appeared in Finland, Germany and the United Kingdom. These vials had been intentionally compromised, e.g., absence of active pharmaceutical ingredient (API), diluted API and/or damaged vial integrity with loss of sterility.

- In May 2013, seven years after the FDA inspected the Indian pharmaceutical manufacturer Ranbaxy, the USA subsidiary pleaded guilty to intentionally manufacturing and distributing adulterated drugs, e.g., isotretioin, gabapentin and ciprofloxacin. They agreed to resolve false claims allegations, Good Manufacturing Practices (GMP) violations and false statements to the FDA.

The purpose of this perspective article is to consider falsified medicines by a look at the past, the present, and the future.

\section{A Brief Look at The Past}

In $1540 \mathrm{AD}$, King Henry VIII and his English Parliament took steps to regulate drug manufacturing in London's apothecaries, that is, the "Apothecary Drugs, Wares and Stuffs Act". One such newly regulated 
product was "Mithridatium", a concoction reported to be compounded from 41 separate substances. Almost 17 centuries earlier, Mithridatium had first been formulated and declared to be a panacea for many ailments by King Mithridates VI of Pontus, then a kingdom in southeastern Europe. Did Parliament's 1540 AD apothecary regulation help protect the public health? History does not record the Act's benefits or lack thereof; history does record that Mithridatium was still being manufactured in London's apothecaries well over two centuries later

\section{A Closer Look at the Present}

Globalisation and the Internet are the most complex challenges faced in securing the integrity and safety of the global supply and distribution chain of medicines and are a gateway to falsified medicines. Today, a majority of the almost one billion people who live in the EU and NA have access via the Internet to thousands of online pharmacies [1], both regulated and unregulated-worldwide. There was an estimated worldwide population of more than 7.2 billion in 2014, of which over $45 \%$ were Internet users. In the $\mathrm{EU}$ and $\mathrm{NA}$, the proportions are higher: Europe over $82 \%$, USA over $87 \%$ and Canada over $94 \%$ [2].

The market for falsified medicines is both complex and global. Despite the efforts made by different organisations to fight falsified products, counterfeiters find new opportunities and ways to introduce them into the legitimate supply chain, no matter the consequences to the consumer. The falsified medicines' market involves a series of activities outside the purview of regulatory authority review. This makes it very difficult to obtain precise information on which to estimate the market size. The IMS database estimates the market size of the legitimate market for 2014 as USD 1.06 trillion (Figure 1A); however, there are no verifiable estimates for the market size of falsified medicines (Figure 1B).
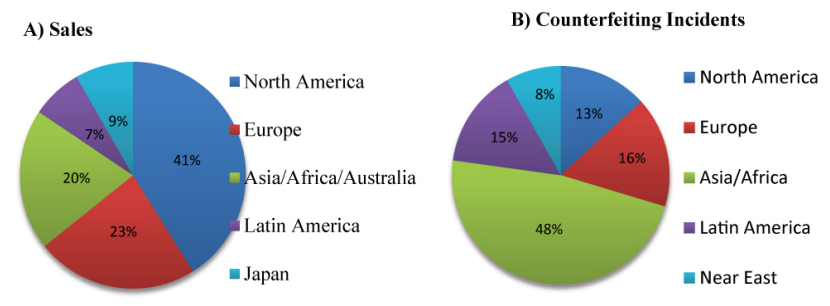

Figure 1: The geographic distribution of (A) pharmaceutical sales (IMS, 2015) and (B) counterfeiting incidents recorded by the Pharmaceutical Security Institute (2014).
In 2006 the International Medical Products Anti-Counterfeiting Taskforce (IMPACT) estimated some figures that have not yet been updated: in industrialised and developed countries with strong regulatory systems, the falsified medicines' market was less than $1 \%$ of the total market value, whereas in Africa, Asia or Latin America it was around $30 \%$ [3]. Moreover, Internet sales of falsified medicines worldwide were estimated to be over $50 \%$ of the medicines bought, suggesting that this challenge remains widely uncontrolled. Besides the striking differences between continents, there are also dramatic variations within cities in the same country or with rural areas, where falsified medicines may be openly sold in market places. In addition to this, the instances of EU customs seizing falsified medicines are increasing: in the United Kingdom alone, 15 known incidents of falsified medicines between 2005-2011and it is thought that over 500,000 packs remained in the hands of patients in one incident alone [4].

There are different drivers for counterfeiters that vary from country to country. Examples include: the opportunity for enormous illegal profits, lack of awareness among health professionals and patients, complex supply and distribution chain, lack of political will or susceptibility of officials to bribery, poor enforcement of already inadequate current regulations, weak penal sanctions, high cost and insufficient supply of medicines by the regulated market, ineffective cooperation among the stakeholders (regulatory agencies, industry, trade, customs), illiteracy of the population, and the ever increasing expansion of global trade.

\section{Current Regulations In Developed Countries - Is It Enough?}

The process of distributing medicines-legitimate or falsifieddepends on the supply and distribution chain. The legitimate supply chain has been defined as "any supply chain that is either regulated/ licensed by a ministry of health or other regulatory body (or) any supply chain where a patient would reasonably expect to obtain authentic product, supplied via a controlled supply chain, from the manufacturer of the product to the point of dispensing" [5].

Being aware of this global public health crisis and the weakest links, government authorities are developing more stringent environments (Table 1) to impede the breach of the legitimate supply chain. To protect public health, cooperation on the part of all legitimate stakeholders and collaboration of not-for-profit organisations are crucial for the collection of more comprehensive and timely information.

\begin{tabular}{|l|l|l|l|}
\hline Area & Regulatory Authority & Regulatory Landscape & Latest publication \\
\hline \multirow{2}{*}{ EU } & \multirow{2}{*}{ EMA } & Directive 2011/62/EU (Falsified Medicines Directive) & 2011 \\
\cline { 3 - 4 } & & Directive 2001/83/EC (Medicines for human use) & 2001 \\
\hline \multirow{2}{*}{ USA } & \multirow{2}{*}{ FDA } & Drug Quality and Security Act & 2013 \\
\cline { 3 - 4 } & & Food and Drug Administration Safety and Innovation Act & 2012 \\
\hline & Health Canada & Controlled Drugs and Substances Act & 2015 \\
\hline
\end{tabular}


Citation: Lain Abril J, Holt DW, Wilson RR (2016) Falsified Medicines in the European Union and North America: What are we doing to Protect

Page 3 of 4

\begin{tabular}{|l|l|l|l|}
\hline \multirow{4}{*}{ Canada } & Food and Drugs Act & 2014 \\
\cline { 3 - 4 } & Compliance and Enforcement Policy & 2005 \\
\cline { 3 - 4 } & $\begin{array}{l}\text { Health Products and Food Branch Inspectorate Policy on Counterfeit Health } \\
\text { Products }\end{array}$ & 2010 \\
\hline
\end{tabular}

Table 1: Overview of the falsified medicines regulatory landscape in Europe and North America (excluding Mexico). European Medicines Agency (EMA); United States Food \& Drugs Administration (FDA).

The European Union published Directive 2011/62/EU, an amendment of Directive 2001/83/EC, as regards the prevention of the entry into the legal supply chain of falsified medicinal products [6] and is most commonly known as the Falsified Medicines Directive (FMD). The FMD defines "falsified medicine product" and focuses on four pillars to secure the legitimate supply and distribution chain from such medicines: 1) the active pharmaceutical ingredient (API), 2) good distribution and good manufacturing practices, 3) safety features, and 4) online sales of medicinal products. Member States have until 2018 to fully comply with this directive.

In NA, the USA has two main acts that propose anti-counterfeiting actions: Title II of the Drug Quality and Security Act and Title VII of the Food and Drug Administration Safety and Innovation Act $[7,8]$. They define "illegitimate product", provide guidance for identifying suspect and illegitimate products and the way forward for manufacturers, re-packagers, wholesale distributors, and dispensers; they have a timeframe of ten years to be compliant. The regulatory landscape in the USA is slightly different from that in the EU. Nearly $40 \%$ of the final pharmaceutical products and about $80 \%$ of the APIs used in the USA are imported from elsewhere [9], which is why these acts apply not only to USA products but also any other product that is intended to be imported into the USA.

Health Law in Canada is published four times a year. The main two acts that refer to medicinal products are Food and Drugs Act and the Controlled Drugs and Substances Act $[10,11]$. These acts define "deception" and specify that the sale of counterfeit health products is also a violation of the Criminal Code. In addition to these Acts, Canada has in place several policies to avoid counterfeiting: Compliance and Enforcement Policy and Health Products and Food Branch Inspectorate Policy on Counterfeit Health Products [12,13]. These policies aim to mitigate the risks posed by falsified medicines and to promote safety and quality in the Canadian supply chain, thereby, identifying, assessing, and managing health risks. They also lay out the responsibilities of regulated parties, consumers and health care professionals in ensuring the safe and effective manufacture and use of health care products.

\section{An Enquiring Look to the Future}

Protecting the health of the patient and ensuring high quality, safe and effective medicines must be the highest priority of healthcare providers and the pharmaceutical industry. To achieve this, in March 2013, 29 of the world's largest pharmaceutical companies funded a three-year INTERPOL programme worth almost USD five million. The aim of this programme is to fight against pharma-crime focusing on the enforcement of regulations, expanding training and capacity building opportunities for the police, and raising public awareness of the dangers of falsified medicines, especially those purchased using the Internet.
The manufacturers and distributors of pharmaceuticals are not the only groups concerned in the fight against falsified medicines. Healthcare professionals must also an active part. The healthcare professional, as last link of the supply and distribution chain, is responsible for the medicines provided and needs to be able to guarantee the quality and safety to ensure the wellbeing of patients.

Hippocrates (Greece, c460-c370 BC) offers wisdom as we look forward: "As to disease, make a habit of two things: help, or at least, do no harm". The Hippocratic Oath was composed more than 2,400 years ago, but the first recorded use outside Greece was in $1508 \mathrm{AD}$ in Germany, and it was translated into English in the 18th century [14]. This Oath is a declaration to practice medicine justly and ethically, focusing on professional behavior, educating the patients and guarding their wellbeing.

With these thoughts in mind, a few questions may be considered:

- Do our patients receive legitimate or falsified medicines when filling our prescriptions?

- If our patients order medicines via the Internet what are they obtaining?

- Do we as healthcare providers know the public health impact of falsified medicines?

- Do we as healthcare provider colleagues - i.e. pharmacists, physicians, nurses, discuss this?

- Do we know if our elected government representatives know about falsified medicines?

- What specific steps as healthcare providers ought we to take next?

Based on these considerations of the past and the present, the following specific recommendations need careful consideration by healthcare professionals, patient advocacy groups, pharmaceutical companies, national healthcare delivery systems, regulatory authorities, police, customs, and Internet providers:

- Secure and protect the legal supply and distribution chain by more effective enforcement of existing regulations.

- Tighten the current regulations regarding Internet trade in medicines.

- Unite the fight against falsified medicines globally, promoting cooperation among all parties involved in the access to medicines.

- Promote awareness campaigns and training to educate consumers and healthcare professionals, and provide incentives for an ethical behavior at all levels.

\section{Acknowledgement}

This article is based on research made for an MSc dissertation funded by University College London and supervised by Khalid A. Sheikh, PhD. 
Citation: Lain Abril J, Holt DW, Wilson RR (2016) Falsified Medicines in the European Union and North America: What are we doing to Protect Public Health?. J Pharmacovigil 4: 213. doi:10.4172/2329-6887.1000213

Page 4 of 4

\section{Conflict of Interest}

We have read and understood the BMJ Group policy on declaration of interests and declare the following interests: Miss Lain Abril reports grants from University College London, School of Pharmacy, during the conduct of her dissertation.

David Holt has received speaker fees from Novartis Pharma and Sanofi for lectures to clinicians and drug regulators on the clinical impact of substandard medications.

Dr. Wilson has nothing to disclose.

\section{References}

1. John C. Horton (2015) Executive Summary of Testimony. LegitScript.

2. Internet World Stats (2014) Internet usage statistics.

3. Johnston A, Holt DW (2013) Substandard drugs: a potential crisis for public health. Br J Clin Pharmacol 78: 218-243.

4. Royal Pharmaceutical Society Policy Statement (2013) Falsified medicines directive (FMD).

5. Mackey TK, Liang BA, York P, Kubic T (2015) Counterfeit drug penetration into global legitimate medicine supply chains: a global assessment. Am J Trop Med Hyg 92: 59-67.
6. Directive 2011/62/EU, an amendment of Directive 2001/83/EC, as regards the prevention of the entry into the legal supply chain of falsified medicinal products.

7. Title II of the Drug Quality and Security Act.

8. Public Law 112-114 (2012) 112th Congress, Food and Drug Administration Safety and Innovation Act (FDASIA). Title VII: Drug Supply Chain Provisions

9. Bate R, Mathur A, Lever HM, Thakur D, Graedon J et al. (2015) Generics Substitution, Bioequivalence Standards and Oversight of International Pharmaceutical Producers: Complex Issues Facing the FDA. Trends Pharmacol Sci 37: 184-191.

10. An Act respecting food, drugs, cosmetics and therapeutic devices (2014) Government of Canada.

11. Controlled Drugs and Substances Act (2016) Government of Canada.

12. Compliance and Enforcement Policy (2005) Health Canada.

13. Policy on Counterfeit Health Products (2010) Health Canada.

14. Hulkower R (2010) The History of the Hippocratic Oath: Outdated, Inauthentic, and Yet Still Relevant. The Einstein Journal of Biology and Medicine 41-44. 